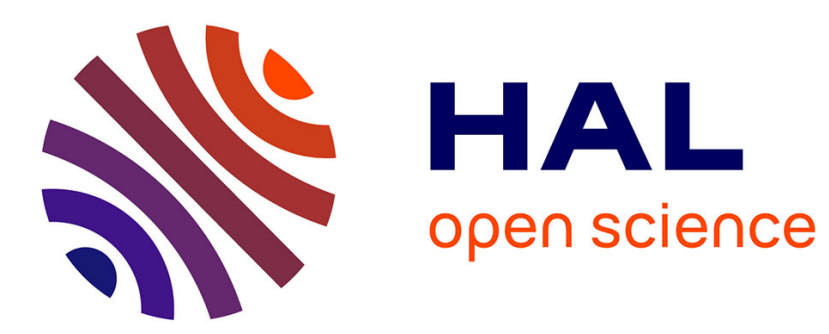

\title{
Predicting the Ductile Failure of DP-steels Using Micromechanical Modeling of Cells
}

\author{
F.M. Al-Abbasi, James A. Nemes
}

\section{To cite this version:}

F.M. Al-Abbasi, James A. Nemes. Predicting the Ductile Failure of DP-steels Using Micromechanical Modeling of Cells. International Journal of Damage Mechanics, 2008, 17 (5), pp.447-472. 10.1177/1056789507077441 . hal-00571170

\section{HAL Id: hal-00571170 \\ https://hal.science/hal-00571170}

Submitted on 1 Mar 2011

HAL is a multi-disciplinary open access archive for the deposit and dissemination of scientific research documents, whether they are published or not. The documents may come from teaching and research institutions in France or abroad, or from public or private research centers.
L'archive ouverte pluridisciplinaire HAL, est destinée au dépôt et à la diffusion de documents scientifiques de niveau recherche, publiés ou non, émanant des établissements d'enseignement et de recherche français ou étrangers, des laboratoires publics ou privés. 


\title{
Predicting the Ductile Failure of DP-steels Using Micromechanical Modeling of Cells
}

\author{
F. M. Al-ABBASI* \\ University of Bahrain, Department of Mechanical Engineering \\ PO Box 32038, Isa Town, Kingdom of Bahrain \\ JAMES A. NEMES \\ Department of Mechanical Engineering, McGill University \\ 817 Sherbrook St. West, Quebec, Canada H3A 2K6
}

\begin{abstract}
Thus far, micromechanical modeling of cells has been used successfully to capture the deformation behavior of dual phase (DP) steels, which display impressive mechanical properties, especially for the automotive industry. However, the prediction of ductile failure, which is essential in the manufacture and design of parts, needs to be modeled in order to develop a model, which can fully characterize DP-steels. The Gurson-Tvergaard (GT) damage model is coupled with a micromechanical model developed in earlier works, which captures the deformation behavior of DP-steels well, making a complete material model. A procedure that accounts for damage in terms of the void volume fraction, stress triaxiality and the mechanics of failure in DP-steels as major damage factors, is developed in this work to determine the calibrating parameters in the GT yield function. When these parameters are determined, they are employed in numerical simulations of a tensile bar test to compare the experimental and numerical fracture parameters. The results show good agreement between the numerical predictions using the GT parameters obtained by the procedure developed in the current work and the experimental findings at different levels of volume fraction of martensite $\left(V_{\mathrm{m}}\right)$. It is also shown that the GT parameters obtained using a calibrating procedure, which ignores the local deformation behavior of the material, does not produce the appropriate parameter values.
\end{abstract}

KEY WORDS: dual phase steel, damage models, fracture, calibrating procedure, micromechanical modeling, macromechanical modeling.

*Author to whom correspondence should be addressed. E-mail: falabbasi@eng.uob.bh Figures 1-9 appear in color online: http://ijd.sagepub.com

International Journal of DAmage Mechanics, Vol. 17-September 2008 


\section{INTRODUCTION}

D UAL PHASE (DP) steels offer attractive mechanical properties, especially for the automotive industry, such as high strength, continuous yielding, high work hardening rate, and good ductility in addition to high crash resistance, reduced cost, good formability, and excellent surface finish, due to the elimination of the yield point elongation. The application of DP-steels in automotive components such as bumpers, wheels, wheel discs, pulleys, springs, etc. have shown a weight reduction of up to $30 \%$ with an increase in component life (Abdalla et al., 1999). These steels are also reported to display high crashworthiness features, due to the combined strength and ductility they display, which is why they are used in the crash sensitive parts in the front and rear rails of automobiles.

Dual phase steels which are produced by the intercritical heat treatment of low carbon steels, possess a composite microstructure consisting of martensite dispersed in a softer phase known as ferrite. The mechanism of failure of DP-steels reportedly occurs in a ductile manner by void nucleation, growth, and finally coalescence. The fracture mechanics approach, which is based on a well-founded mathematical background, fails to address this aspect of failure due to several reasons. The most important reason is that the basic philosophy in the conventional fracture mechanics, which uses global fracture parameters such as the J-integral, works only in some limited cases, and often the assumption of the existence of a macroscopic flaw in the material does not correspond to the real material at hand and thus does not account for the characteristics of the material (Gdoutos, 1993).

The attractive mechanical properties of DP-steels are attributed to their microstructure and, consequently, modeling the mechanical behavior of such materials has to be done based on the microstructural levels, which are many, but only the phase level of the material can be considered as an isotropic continuum. Micromechanical modeling of cells has been used in previous works to characterize the DP-steels. Detailed investigations were presented and a model was developed which can particularly capture the deformation behavior of DP-steels (Al-Abbasi and Nemes, 2003a,b; Al-Abbasi and Nemes, 2007).

The above model can predict the deformation behavior of DP-steels, which enabled it to predict the yield strength, UTS, the uniform strain, and the strain-hardening rate. However, this model does not embody a fracture criterion, which would enable it to predict the limiting elongation to fracture. As mentioned earlier, the ductile failure of DP-steels occurs by the process of void nucleation, growth, and coalescence. For a void-containing material, the most widely-known and used material damage model is the 
Gurson-Tvergaard (GT) model, which has been discussed in the literature. The results of the micromechanical model developed in previous works are coupled with the GT model to describe the deformation and fracture behavior of the DP-steels. The calibrating parameters in the GT yield function are determined uniquely by a procedure developed in this work. The main objective of the current research work is to present a model that can predict the failure behavior of DP-steels in addition to being able to characterize their deformation behavior, which has been the subject of previous works. The model above can then be used to understand the deformation and fracture behavior of DP-steels, which can lead to optimum design of these steels with enhanced properties.

\section{EXPERIMENTAL RESULTS}

\section{Materials}

A low carbon DP-steel consisting of martensite dispersed in an equiaxed ferrite is used in this work. The above material was received in the form of a wire rod of diameter $10 \mathrm{~mm}$ and chemical composition, determined using vacuum emission spectroscopy in wt. $\%$, of $0.09 \mathrm{C}, 1.5 \mathrm{Mn}, 0.98 \mathrm{Si}, 0.06 \mathrm{Cr}$, $0.08 \mathrm{Ni}, 0.005 \mathrm{~S}, 0.01 \mathrm{P}, 0.004 \mathrm{Mo}, 0.005 \mathrm{~N}$, and $0.04 \mathrm{Cu}$. This material was cut into the shape of cylindrical bars and quenched in water from different intercritical temperatures to room temperature to obtain DP-steels of different volume fraction of martensite $\left(V_{\mathrm{m}}\right)$. The heat treatment details are presented in Table 1. The single ferrite phase was also produced (as shown in Table 1) which is required to model the material micromechanically which will be shown later. The heat treatment to produce ferrite was carried out by decarburizing the steel for $21 \mathrm{~h}$ at $1000^{\circ} \mathrm{C}$ followed by furnace cooling, to produce a carbon free steel. This process of heat treatment produced $6 \%$ pearlite in addition to ferrite, which is a good approximation of the ferrite phase as the pearlite phase is not much stronger than the ferrite phase and due to its low percentage, would not have significant influence on the material behavior. To remove decarburized layers on the tensile samples,

Table 1. Heat treatment details and volume fraction of martensite produced.

\begin{tabular}{lcc}
\hline $\boldsymbol{V}_{\mathrm{m}}(\%)$ & Annealing temperature $\left({ }^{\circ} \mathbf{C}\right)$ & Time \\
\hline 14.0 & $750^{\circ} \mathrm{C}$ & $15 \mathrm{~min}$ \\
19.7 & As received & As received \\
34.0 & $825^{\circ} \mathrm{C}$ & $10 \mathrm{~min}$ \\
Ferrite & $1000^{\circ} \mathrm{C}$ & $21 \mathrm{~h}$ \\
\hline
\end{tabular}


they were machined to $6 \mathrm{~mm}$ diameter, which also ensures a uniform heat treatment through the diameter.

\section{Mechanical Testing}

After heat treating the cylindrical bars according to Table 1, tensile specimens with threaded ends were made from them and tested in uniaxial tension on a Material Testing Systems (MTS) machine which is equipped with an automatic controller using the displacement control mode at a quasi static rate of $0.05 \mathrm{~mm} / \mathrm{s}$. A one-inch extensometer was used to measure the strain in the specimens. The ratio of the gauge length to the diameter is taken as nearly $4: 1$. The tensile tests were performed at room temperature and the resulting load-strain data obtained directly from the MTS machine was converted to engineering stress-strain curves. The single ferrite phase produced as shown in Table 1 was also tested to get the ferrite phase behavior. Three to four specimens for each $V_{\mathrm{m}}$ were tested. The repeatability of the results was excellent and almost all the necking occurred between the extensometer pins.

\section{Microstructure}

Figure 1 shows representative optical micrographs of DP-steels produced in this work. The specimens examined for microstructure were cut from the threaded portion of the specimen as this region undergoes minimum deformation. The samples were ground using a series of silicon carbide papers and polished using diamond paste and finally etched using a $2 \%$ nital solution. The volume fractions were determined using a Clemex vision version 3.5 image analyzer equipped with a Nikon model Epiphot 200 optical microscope, based on area percent. In order to obtain a good representation of the microstructure, a magnification of 500 times was chosen and 16 fields in each of the four coordinate directions and in the diagonal directions in addition to the center of the specimen was measured in each specimen examined. In the microstructures shown in Figure 1, the bright grains are the ferrite phase and the dark ones are the martensite. These microstructures show how the martensite phase is distributed in the ferrite matrix at each level of $V_{\mathrm{m}}$ considered. Figure $1(\mathrm{c}-1)$ and (c-2) represent the material at $V_{\mathrm{m}}=34 \%$ at different locations of the analyzed sample. These show how close the distribution of martensite is at different locations of the sample. Figure 1(d-1) and (d-2) show representative single ferrite at two different locations of the sample which show low percent pearlite precipitate everywhere. 


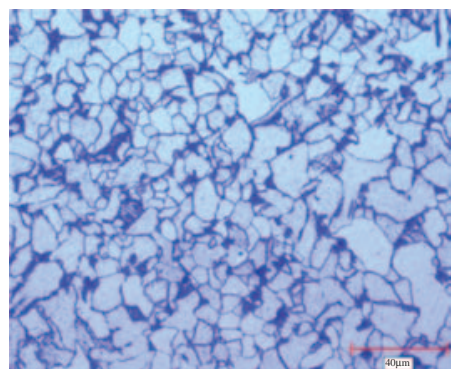

(a)

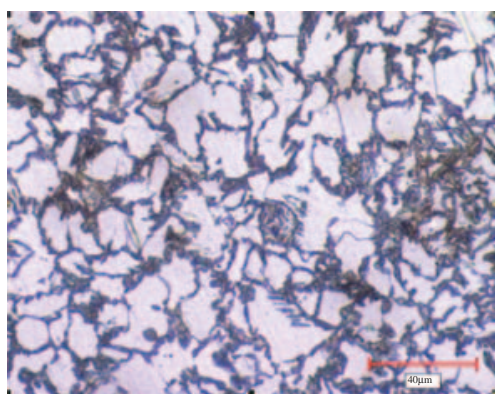

(c-1)

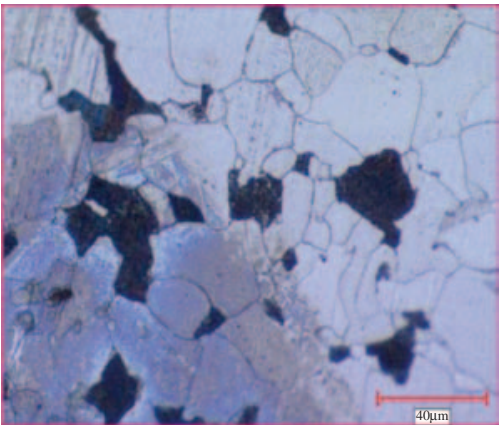

(d-1)

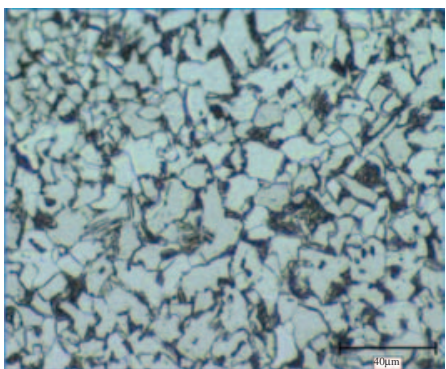

(b)

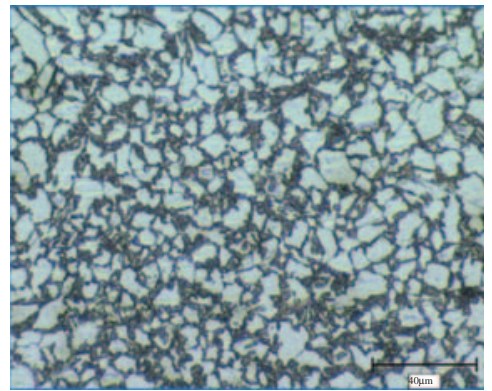

(c-2)

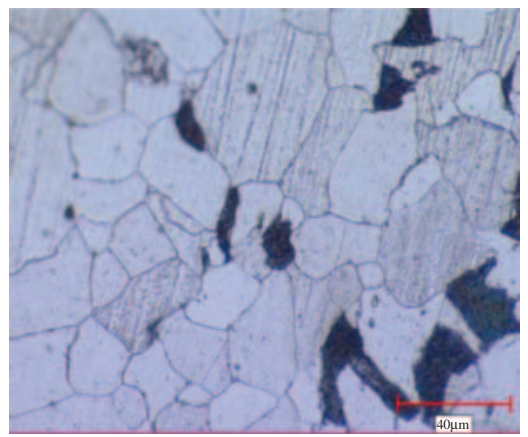

(d-2)

Figure 1. Micrographs of typical microstructures produced in this work: (a) $V_{m}=14 \%$; (b) $V_{m}=19.7 \%$; (c) $V_{m}=34 \%$; and (d) Single ferrite phase with $6 \%$ pearlite.

\section{MICROMECHANICAL MODELING OF CELLS}

Micromechanical analysis of multiphase materials provides aggregate behavior from known properties of the individual constituents and their interface interaction. In previous work by Al-Abbasi and 
Nemes (2003a), it was shown that the idealization based on the stacked hexagonal array (SHA) model could well capture the mechanics and mechanisms of deformation of DP-steels. The SHA model was shown to capture the experimental results reported in the literature, both in terms of the stress-strain behavior and in terms of the deformation fields of the constituents at several levels of $V_{\mathrm{m}}$. On the other hand, the idealizations based on plane strain models were shown to overpredict the strain hardening behavior of the material at intermediate and high $V_{\mathrm{m}}$, which misinterpret the deformation fields of the constituents and the interaction between each. Al-Abbasi and Nemes (2003b) have extended the same axisymmetric model but made it with two particle sizes to account for particle size distribution. The idealization based on the two particle sizes was shown to be a more realistic assumption in this kind of material and better represents the behavior of DP-steels. Al-Abbasi and Nemes (2007) have shown that the above model which considers particle size distribution, when coupled with the effect of carbon dilution and grain size difference, compares very well with experimental observations. In this work, the model above will be utilized with certain modifications to predict fracture behavior of DP-steels.

In micromechanical modeling, the behavior of each constituent is required which can be determined by tests on the material consisting of a single constituent. For steels, this is achievable by annealing the steel to a designed temperature level and then cooling at controlled rates using the time temperature transformation (TTT) diagram to get the desired single phase. The single-phase steel can then be tested mechanically to obtain the mechanical behavior of that specific phase. The interaction of phases (interface boundaries) will be ignored, as it is considerably small, on the order of few atomic sizes, compared to the phases being modeled. Thus, the boundary will be considered a cohesive interface, although from the metallurgical viewpoint this is not absolutely true as the boundary between the ferrite and the martensite is an interface between different crystal types which is not a cohesive interface, but from the mechanical point of view the interface is strong enough to be assumed cohesive for the mechanics and mechanism of deformation to be investigated compared to the noncohesive boundaries. Therefore, a perfectly continuous boundary between the ferrite and martensite has been used in the micromechanical model. Each phase is considered to be an elastic plastic solid and it is assumed that the total strain increment can be decomposed into the elastic and plastic components:

$$
\mathrm{d} \varepsilon_{i j}^{t}=\mathrm{d} \varepsilon_{i j}^{e}+\mathrm{d} \varepsilon_{i j}^{p}
$$


The plastic strain rate is given as:

$$
\begin{aligned}
\mathrm{d} \varepsilon_{i j}^{p} & =0 \quad f<0 \\
\mathrm{~d} \varepsilon_{i j}^{p} & =\frac{3}{2} \frac{\mathrm{d} \varepsilon_{\mathrm{e}}^{p}}{\sigma_{\mathrm{e}}} \sigma_{i j}^{\prime} \quad f=0 .
\end{aligned}
$$

Where, the deviatoric stresses $\sigma_{i j}^{\prime}=\sigma_{i j}-1 / 3\left(\sigma_{k k}\right)$ and the effective stress, $\sigma_{\mathrm{e}}$, and the effective plastic strain rate, $\mathrm{d} \varepsilon_{\mathrm{e}}^{p}$, are defined as:

$$
\begin{aligned}
\sigma_{\mathrm{e}} & =\sqrt{\frac{3}{2} \sigma_{i j}^{\prime} \sigma_{i j}^{\prime}} \\
\mathrm{d} \varepsilon_{\mathrm{e}}^{p} & =\sqrt{\frac{2}{3} \mathrm{~d} \varepsilon_{i j}^{p} \mathrm{~d} \varepsilon_{i j}^{p} .}
\end{aligned}
$$

The von Mises yield condition is assumed:

$$
f=\sigma_{\mathrm{e}}-\bar{\sigma}
$$

where $\bar{\sigma}$ is a function of the effective plastic strain and is taken to describe the isotropic hardening. The martensite material behavior is adopted from Davies (1978), as martensite strength characteristics are carbon dependent only and thus it would be sufficient to know the carbon content to adjust martensite strength. The ferrite material behavior obtained from the single ferrite phase made in this work as shown earlier, is used to describe the plastic material behavior in the micromechanical model. Alloying elements have considerable effect on the behavior of the material and this phase behavior has to be produced for any material when the prediction of the material behavior is sought.

The hardening behavior of martensite is taken from the experimental results reported by Davies (1978) and expressed by the following:

$$
\bar{\sigma}_{\mathrm{m}}=K_{\mathrm{m}}\left(\varepsilon_{0}+\varepsilon_{\mathrm{m}}^{p}\right)^{n_{\mathrm{m}}}
$$

where the subscript $\mathrm{m}$ denotes martensite, $\varepsilon_{0}$ is 0.002 in this work, and $n_{\mathrm{m}}$ is 0.07 (Davies, 1978). The values of the ultimate stress for the single martensite phase and the values of $n_{\mathrm{m}}$ reported by Davies (1978) are utilized in a power law relation to get $K_{\mathrm{m}}$, which was found to be $2409 \mathrm{MPa}$. The experimental behavior of the ferrite was fitted using two equations, namely a logarithmic equation and a power law equation, as one equation is 
not able to characterize the material behavior throughout the range of interest and is mathematically expressed as follows:

$$
\bar{\sigma}_{f}=\left\{\begin{array}{l}
920\left(\varepsilon_{0}+\varepsilon_{f}^{p}\right)^{0.2556} \text { for } 0.002 \leq \varepsilon_{f}^{p} \leq 0.15 \\
109 \operatorname{Ln}\left(\varepsilon_{0}+\varepsilon_{f}^{p}\right)+753.4 \text { for } \varepsilon_{f}^{p} \geq 0.15
\end{array}\right.
$$

where $f$ denote ferrite, $\varepsilon_{0}$ is taken to be 0.002 , and $\varepsilon_{f}^{p}$ is ferrite plastic strain. The single ferrite and martensite behaviors have been chosen to be continuous from the instability point onwards. Large strains are considered in the ferrite case because the ferrite phase experiences large plastic deformations on the microstructural level especially at the ferrite martensite interface. The stress versus plastic strain for the ferrite and martensite phases is shown in Figure 2. The difference in uniform elongation is shown better by considering the behavior under uniaxial tension stress. Under the above conditions, the effective stress reduces to the true uniaxial stress, $\sigma$, and the effective plastic strain is equal to true strain, $\varepsilon$. The engineering and true stresses and strains are related as follows:

$$
\begin{aligned}
e & =\exp (\varepsilon)-1 \\
\sigma_{n} & =\frac{\sigma}{(1+e)} .
\end{aligned}
$$

For uniaxial loading, the engineering stress versus strain is also shown in Figure 2, where the difference in uniform strain for the two phases is quite apparent. ${ }^{1}$

In many previous treatments reported in the literature, modeling DP-steels has been performed in order to predict the deformation behavior of the material. As demonstrated by Al-Abbasi and Nemes (2007), this has been done quite successfully. However, in those treatments there were no fracture criteria employed and therefore, the model could not predict the limiting strain value (fracture) of the aggregate under tensile loading. The ductile failure of DP-steels occurs by the process of void nucleation, void growth, and finally void coalescence. For a void-containing material, the most widely-known material damage model is the GT model, which has been reported comprehensively in the literature. This model was the first to account for material softening reflected in the yield function, which was a great success in modeling ductile material failure. On the other hand, due to

\footnotetext{
${ }^{1}$ It should be noted that no fracture criteria has been employed at this stage, therefore, the response shown cannot predict the limiting strain value of the phase under tensile loading.
} 


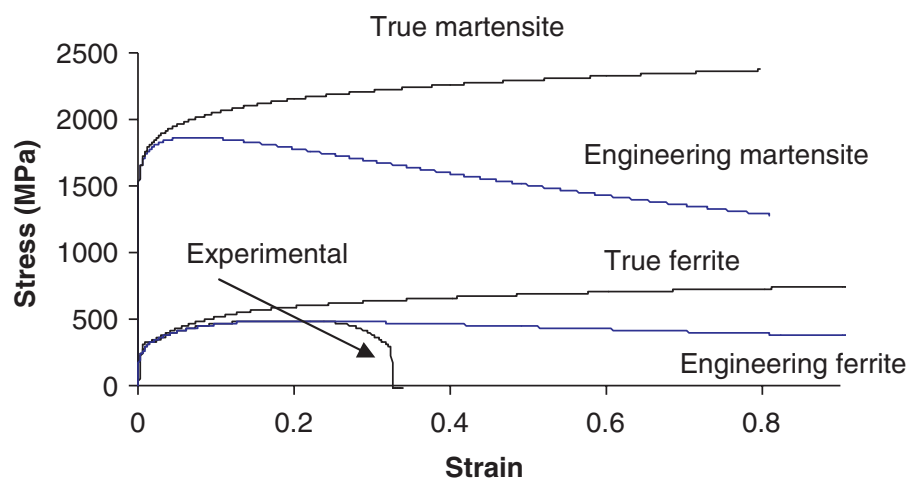

Figure 2. Idealized behavior of the martensite and ferrite shown as true stress vs true strain and engineering stress vs engineering strain for uniaxial tensile stress conditions.

some drawbacks, this model went through a series of improvements by Tvergaard and others, because it greatly overpredicts strain to failure in real materials. Even with the improvements mentioned above, the model has no intrinsic ability to predict coalescence i.e., transition from homogeneous to localized deformation mode between voids. However, it has been shown by many workers that this model can adequately capture the failure behavior of many materials that fail by the process of void nucleation, growth, and coalescence using the correct calibrated parameters in each case. This model, although used by many, is also criticized because of its many correcting parameters. However, the rationale that there is no better model than this still prevails. The GT model is a damage model which when coupled with the results of the micromechanical model presented in Al-Abbasi and Nemes (2003b) and Al-Abbasi and Nemes (2007), will make up a complete material model, which will be the subject of the next sections.

\section{FRACTURE MECHANISM OF DP-STEELS}

Dual phase steels have been reported by many authors to fracture in a ductile manner of void nucleation, void growth, and void coalescence. Many investigators like Rashid (1977) and Rashid and Cprek (1978), Gladman (1997) and Balliger (1982) have observed that void formation arises from both martensite particle fracture and interface decohesion. Gladman (1997), Koo and Thomas (1977), and Balliger (1982) stressed that major voids form in the fracture of martensite particles. Sun and Pugh (2002) have observed that the formation of voids takes place by both mechanisms depending on the morphology of the martensite. Steinbrunner and Krauss (1988) observed three mechanisms of void formation, namely, interface decohesion, 
martensite fracture, and uniquely identified martensite separation. Kang and Kwon (1987) studied the fracture behavior of intercritically treated structure in medium carbon steels and observed that the ferrite-martensite interface decohesion was the predominant mode of void nucleation and growth, where martensite structure was the lath type. On the other hand, as the amount of the martensite increases, its shape changes to the plate-like structure, which fails mostly by cleavage (low energy tears) rather than dimples observed in the former case. Kim and Thomas (1981) have reported that the initiation of the void in the DP-steels depends on the morphology of the second phase. They have shown in coarse martensite distribution, that the failure occurs by cleavage of ferrite grains, while for the globular and finely distributed martensite, the void initiation occurs at the ferrite-martensite interface and does not occur at the martensite particles as was reported by others. Others like Gerbase et al. (1979), Speich and Miller (1979), Korzekwa et al. (1980), and Szewczyk and Gurland (1982) have reported that void formation occurs due to martensite-ferrite interface decohesion. Speich and Miller (1979) observed that at low $V_{\mathrm{m}}$, void formation only occurs due to interface decohesion and at high $V_{\mathrm{m}}$ either mechanism forms voids as they have considered $V_{\mathrm{m}}$ as high as $60 \%$. Szewczyk and Gurland (1982) have not observed any particle cracking for $V_{\mathrm{m}}$ in the range $15-20 \%$.

Nam and Bae (1999) have shown that unlike martensite particles aligned nearly parallel to the drawing axis, which are thinned to fibrous shape, those aligned transverse to the drawing axis are severely bent and even fractured with increasing drawing strain. They stated that overwhelming reports find that the majority of voids which lead to fracture are formed at the ferrite-martensite interface, rather than the cracked martensite and eventually coalesce to cause failure during subsequent tensile loading or drawing. Ahmed et al. (2000) have reported three modes of void nucleation, namely martensite cracking, ferrite-martensite interface decohesion, and decohesion at the interfaces with minimum plastic deformation, which has been uniquely identified by them. They reported that at low to intermediate $V_{\mathrm{m}}$ the void formation was due to ferrite-martensite interface decohesion, while the other two mechanisms also occurred at high $V_{\mathrm{m}}$ (above $32 \%$ ).

From the above, it can clearly be seen that void formation occurs mainly by both mechanisms, particle cracking and decohesion of martensite-ferrite interface, at high $V_{\mathrm{m}}$, while at low and intermediate $V_{\mathrm{m}}$ particle cracking is not observed. The preceding observations assert that the failure process in DP-steels occurs mainly by the decohesion of the interface between the ferrite matrix and the martensite particles for the levels of $V_{\mathrm{m}}$ of interest. As a result, in the micromechanical damage model introduced in this work discrete voids are placed at positions of maximum plastic strain (at the 
ferrite-martensite interface) in order to describe the actual failure condition for the DP-steel.

\section{PARAMETER CALIBRATION PROCEDURE}

One of the most well-known damage models which account for the existence of voids in a matrix material is known as the GT model. The GT model assumes a void-containing continuum material, which accounts for the voids in the yield function. The yield function is given by:

$$
\Phi=\left(\frac{\sigma_{\mathrm{e}}}{\sigma_{\mathrm{y}}}\right)^{2}+2 f_{\mathrm{v}} q_{1} \cosh \left(\frac{3 q_{2} \sigma_{\mathrm{h}}}{2 \sigma_{\mathrm{y}}}\right)-\left(1+q_{3} f_{\mathrm{v}}^{2}\right)=0
$$

where $f_{\mathrm{v}}$ is the void volume fraction, $\sigma_{\mathrm{e}}$ is the effective stress, $\sigma_{\mathrm{h}}$ is the hydrostatic stress, and $\sigma_{\mathrm{y}}$ is the yield stress of the fully dense matrix material. Tvergaard suggested the calibrating parameters $q_{1}=1.5$ and $q_{2}=1$ and $q_{3}=q_{1}^{2}$ (Tvergaard, 1981, 1982) to better capture experimental results. Since then, the parameters in the above equation have traditionally been adjusted by fitting the experimental results with finite element predictions using different values of the calibrating parameters in a trial and error fashion (e.g., employing the GT model in a simulation of a tensile bar and comparing the results to the experimental findings). The best fit was considered to be the proper values for the material considered. These values have been used regardless of the material properties, which suggests that the selection of these values (without certain criteria) was done blindly. Faleskog et al. (1998) reported that the 'q' values for several studies made in previous works showed that the parameters selected in this way were not consistent for materials of different strain hardening index and yield strength to stiffness ratio, which provides clear evidence for the need of a robust scheme to determine these calibrating parameters.

Faleskog et al. (1998) and Geo et al. (1998) presented a procedure for choosing the proper calibration parameters for different strain hardening rates of metallic materials, using a three dimensional model for moderate and high strain hardening materials as the parameters suggested by Tvergaard (1981, 1982) and Tvergaard and Needleman (1984) were not adequately capturing the real material behavior at different strain hardening rates. They followed a two-step calibration procedure; in the first step, they used a three dimensional model containing a discrete spherical void to get the values of the parameters and the second was to use those in the GT model simulating a unit cell material which accounts for void existence in a smeared way. 
The calibration procedure Faleskog et al. (1998) have proposed involves using a micro model with homogeneous matrix material containing a discrete void for different levels of strain hardening rates. Although the model they used captures localization occurring in plain carbon steels with voids, they do not necessarily represent multiphase steels. The mechanics and mechanisms of deformation of DP-steels, as shown in Al-Abbasi and Nemes (2003a,b), and Al-Abbasi and Nemes (2007), are quite different from plain carbon steels. Unlike the plain carbon steel, DP-steels undergo a series of mechanisms, while deforming which introduces different strain localizations than the plain carbon steels, which should be considered when parameter calibration is considered. This demonstrates the need for calibrating the GT model using the micro model, which captures the mechanics and mechanisms of deformation taking place in DP-steels.

In the GT model, the void volume fraction $\left(f_{\mathrm{v}}\right)$ which is the current void volume fraction is the damage variable, and $\sigma_{\mathrm{y}}$ is the current flow stress of the matrix material. There are two parameters in Equation (7) that need to be determined (after setting $q_{3}=q_{1}^{2}$ ) in a procedure, which takes into account the void volume fraction as a damage criterion and loading condition, which should be consistent with what occurs in a tensile test bar during fracture. Therefore, these are the two essential failure criteria, which need to be observed in the process of obtaining the calibrating parameters in Equation (7). This can be achieved by employing discrete voids in the micromechanical model, which well describes the deformation behavior of DP-steels to manifest void growth as the material is deformed. Since there are two parameters to be determined, two discrete void sizes can be employed in the micromechanical model separately to get two different deformation responses. The stress triaxiality in the neck of a tensile bar reaches values in the range of 1.2 depending on the material properties. If the two discrete voids are employed in the micromechanical model and the triaxiality is maintained in the triaxiality range corresponding to that in the neck of the tensile bar at failure, the parameters which are obtained by solving the yield function should represent the failure process of the material being considered.

The above calibrating procedure to determine the GT parameters is developed and used in this work. The fully dense matrix material referred to in the GT model will be the micromechanical model, developed in previous works, consisting of ferrite and martensite, at the specific $V_{\mathrm{m}}$ for which the response is sought. The response of the micromechanical model is obtained for the two void sizes (void 1 and void 2). At a strain corresponding to triaxiality of 1.2 , the response of the micro model with void 1 is used to get the variables $f_{\mathrm{v} 1}, \sigma_{\mathrm{e} 1}, \sigma_{\mathrm{h} 1}$, and $\sigma_{\mathrm{y} 1}$. Following the same steps, the micromechanical model response with void 2 is used to get 
$f_{\mathrm{v} 2}, \sigma_{\mathrm{e} 2}, \sigma_{\mathrm{h} 2}$, and $\sigma_{\mathrm{y} 2}$. When the above variables are inserted in Equation (7), it gives two equations with two unknowns $\left(q_{1}\right.$ and $\left.q_{2}\right)$, which can be solved.

\section{CELL MODEL DESCRIPTION}

It was shown in a preceding section that failure of DP-steels occurs mainly by the decohesion of the interface between ferrite matrix and martensite particles for the levels of $V_{\mathrm{m}}$ of interest. In the cell model, the voids are made in such a way that at the interface, extra nodes are inserted in order to disconnect the elements on the martensite side from the element on the ferrite side, which imposes the required noncohesive condition simulating the condition of interface decohesion. The proper stress triaxiality condition in the micro model is controlled by two springs, which are fixed laterally and axially at the sides of the model as shown in Figure 3. The boundary conditions are similar to what was previously used in Al-Abbasi and Nemes (2003b) except for the two springs, which are used to get proper triaxiality conditions. A specified displacement at node ' $d$ ' on the vertical spring $\left(k_{2}\right)$ is applied and node ' $\mathrm{a}$ ' is fixed to develop stress

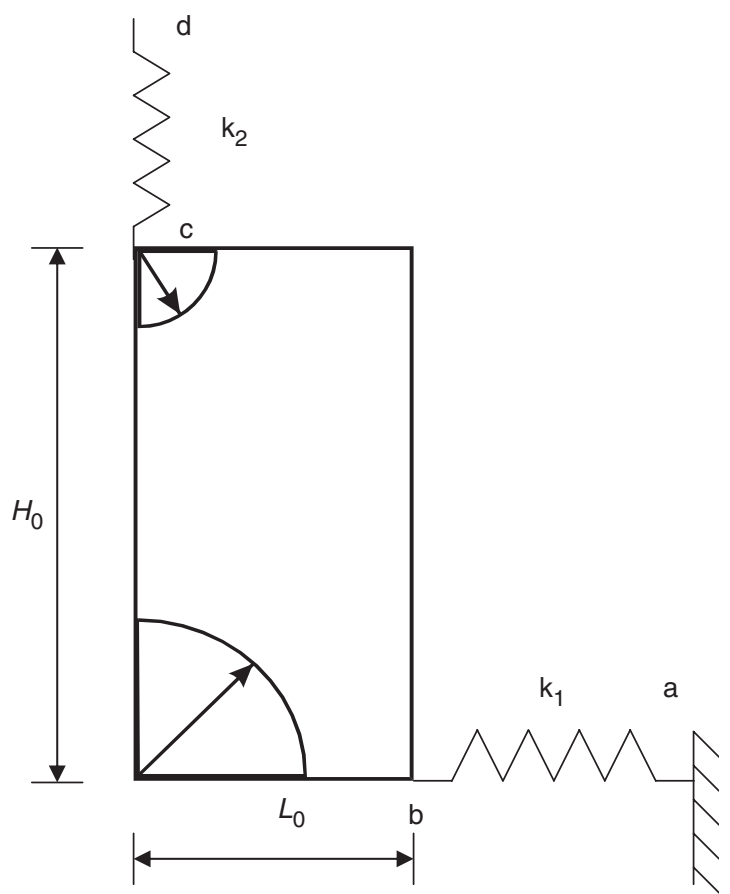

Figure 3. Cell model with two springs and dimensions. 
triaxiality loading condition. The global true stress quantities used to describe the model predictions are:

$$
\begin{aligned}
& S_{11}=\frac{F_{1}}{2 \pi\left(L_{0}+u_{1}^{b}\right)\left(H_{0}+u_{2}^{c}\right)} \\
& S_{22}=\frac{F_{2}}{\pi\left(L_{0}+u_{1}^{b}\right)^{2}}
\end{aligned}
$$

where $F_{1}$ and $F_{2}$ are the concentrated loads in the radial and axial directions, respectively, $u_{1}^{b}$ is the radial displacement of point ' $\mathrm{b}$ ' and $u_{2}^{c}$ is the axial displacement of point ' $c$ ' on the model body. The other dimensions are shown in Figure 3. The global effective and hydrostatic stresses can be expressed as follows:

$$
\begin{aligned}
S_{\mathrm{e}} & =\left|S_{22}-S_{11}\right| \\
S_{\mathrm{h}} & =\frac{1}{3}\left(S_{22}+2 S_{11}\right)
\end{aligned}
$$

and the stress triaxiality, $T$, can be defined as:

$$
T=\frac{S_{\mathrm{h}}}{S_{\mathrm{e}}}
$$

The macroscopic components of strain can be expressed as:

$$
\begin{aligned}
& E_{11}=\int_{L_{0}}^{L} \frac{\mathrm{d} L}{L}=\ln \left(\frac{L}{L_{0}}\right)=\ln \left(\frac{L_{0}+u_{1}^{b}}{L_{0}}\right) \\
& E_{22}=\int_{H_{0}}^{H} \frac{\mathrm{d} H}{H}=\ln \left(\frac{H}{H_{0}}\right)=\ln \left(\frac{H_{0}+u_{2}^{c}}{H_{0}}\right) .
\end{aligned}
$$

From which the effective strain can be expressed as follows:

$$
E_{\mathrm{e}}=\frac{2}{3}\left|E_{22}-E_{11}\right|
$$

\section{PARAMETER DETERMINATION}

The parameters are determined for three levels of $V_{\mathrm{m}}$ considered in this work, namely, $V_{\mathrm{m}}=14,19.7$, and $34 \%$ using the cell model described in the 
previous section. For each case two different martensite-ferrite surface interface decohesion sizes are applied in the micro model at similar stress triaxiality conditions by changing the spring stiffness, which changes the lateral to axial loading ratio. The stress-strain responses for the two void size cases for each $V_{\mathrm{m}}$ considered are shown in Figure 4. The fully dense matrix material response (model response with no void) for each $V_{\mathrm{m}}$ is also added in this figure. The contours of equivalent plastic strain for effective

(a)

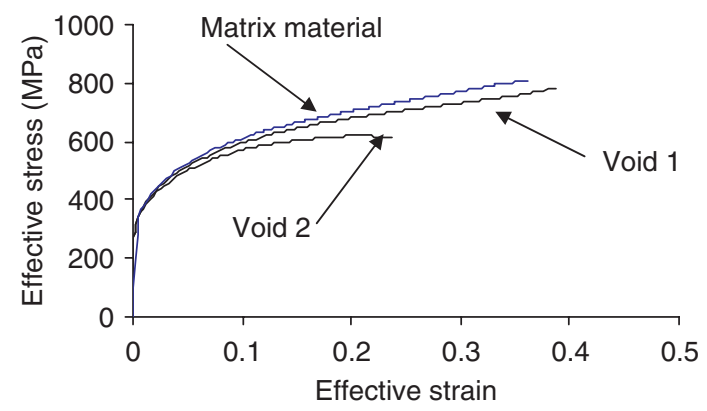

(b)
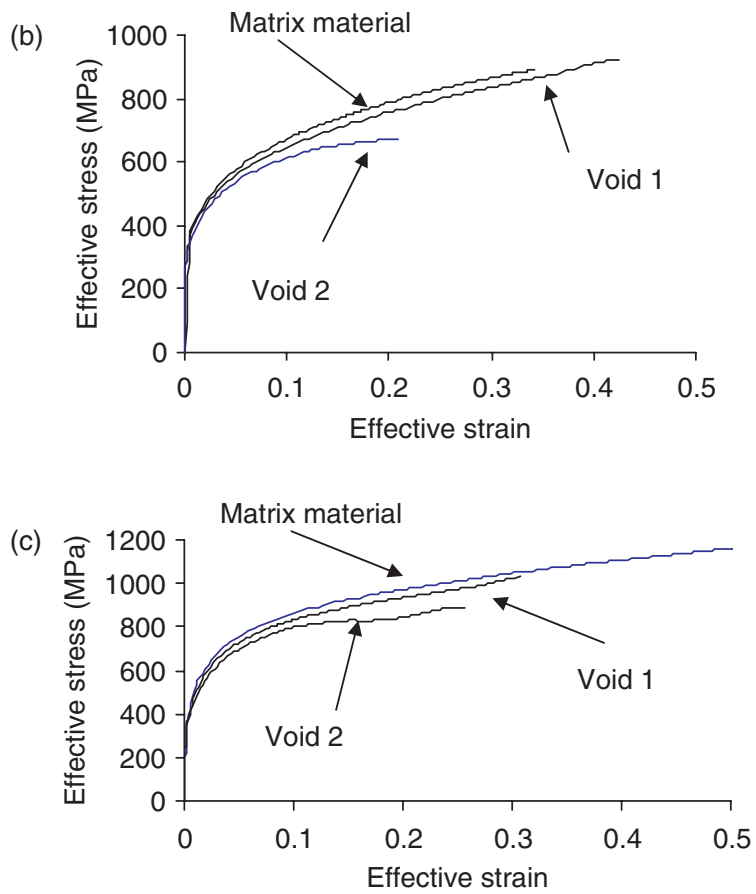

Figure 4. Stress-strain response of the micro model for: (a) $V_{m}=14 \%$; (b) $V_{m}=19.7 \%$; and (c) $V_{m}=34 \%$. 


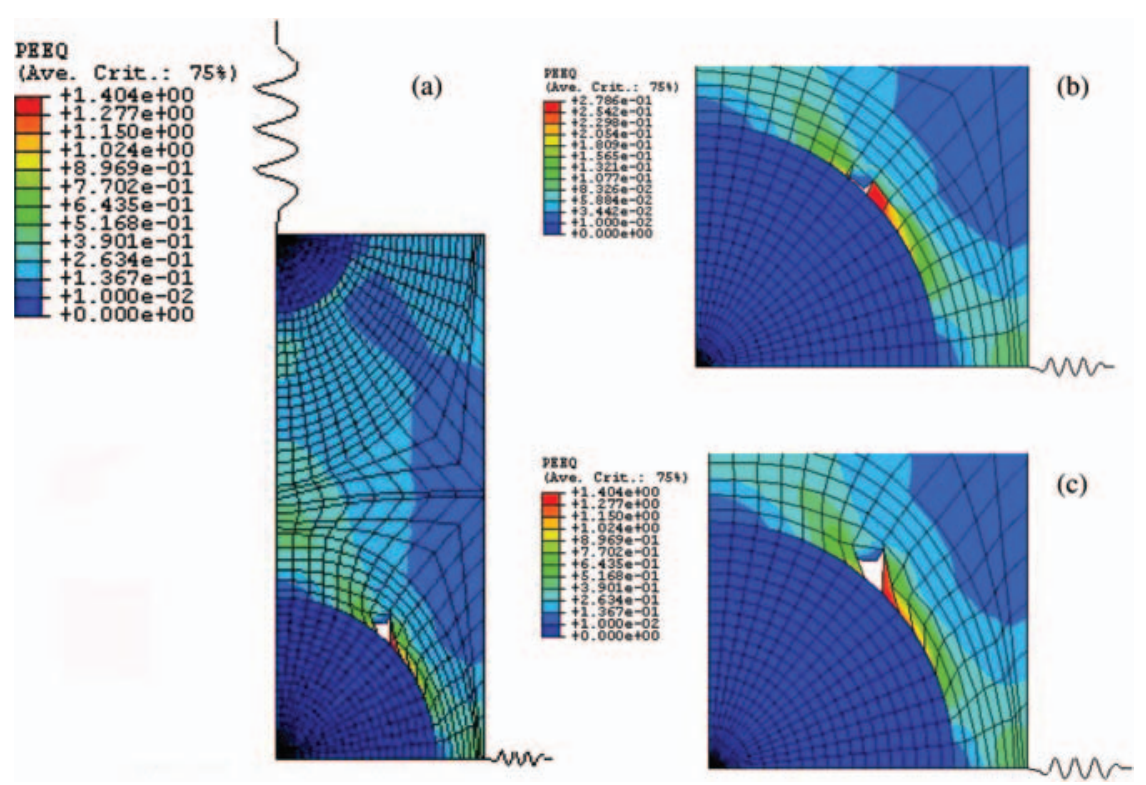

Figure 5a. (a) Contours of plastic strain for $V_{m}=14 \%$, void 1 at $13.5 \%$ effective strain and details of void growth at; (b) $4 \%$; and (c) $13.5 \%$ effective strain.

strains corresponding to triaxiality, $T=1.2$ are shown in Figure 5(a)-(c) for $V_{\mathrm{m}}=14,19.7$, and $34 \%$. The figures depict the void size and growth at the corresponding effective strains. The effective stress-strain curves are determined by evaluating the lateral and axial spring forces in each case to determine the axial and lateral stresses using Equations (8) and (9), from which, using Equation (10) and (11) the effective and hydrostatic stresses are determined. The lateral and axial strains are determined using Equations (13) and (14), from which using Equation (15) the effective strain is calculated. In each void size case at a corresponding $V_{\mathrm{m}}$, the stress triaxiality is measured using Equation (12), as the lateral to axial loading ratio is manipulated by changing the spring stiffness to obtain similar stress triaxiality for both cases up to effective strains of $\sim 20 \%$. At a stress triaxiality of $T=1.2$ for each void case the variables $f_{\mathrm{v}}, \sigma_{\mathrm{e}}, \sigma_{\mathrm{h}}$, and $\sigma_{\mathrm{y}}$ are determined. The void volume fractions were calculated using Catia 5.8. After all the variables were determined, the GT equations for two cases of void volume fractions were solved using Maple 8 to obtain the parameters, $q_{1}$ and $q_{2}$. The variables obtained from the micro model using Figure 4 and the void volume fraction using the contours in Figure 5 are summarized in Table 2. As can be seen in Table 2, the variables $f_{\mathrm{v}}, \sigma_{\mathrm{e}}, \sigma_{\mathrm{h}}$, and $\sigma_{\mathrm{y}}$ for each level of $V_{\mathrm{m}}$ for two void sizes (void 1 and void 2) are determined. 


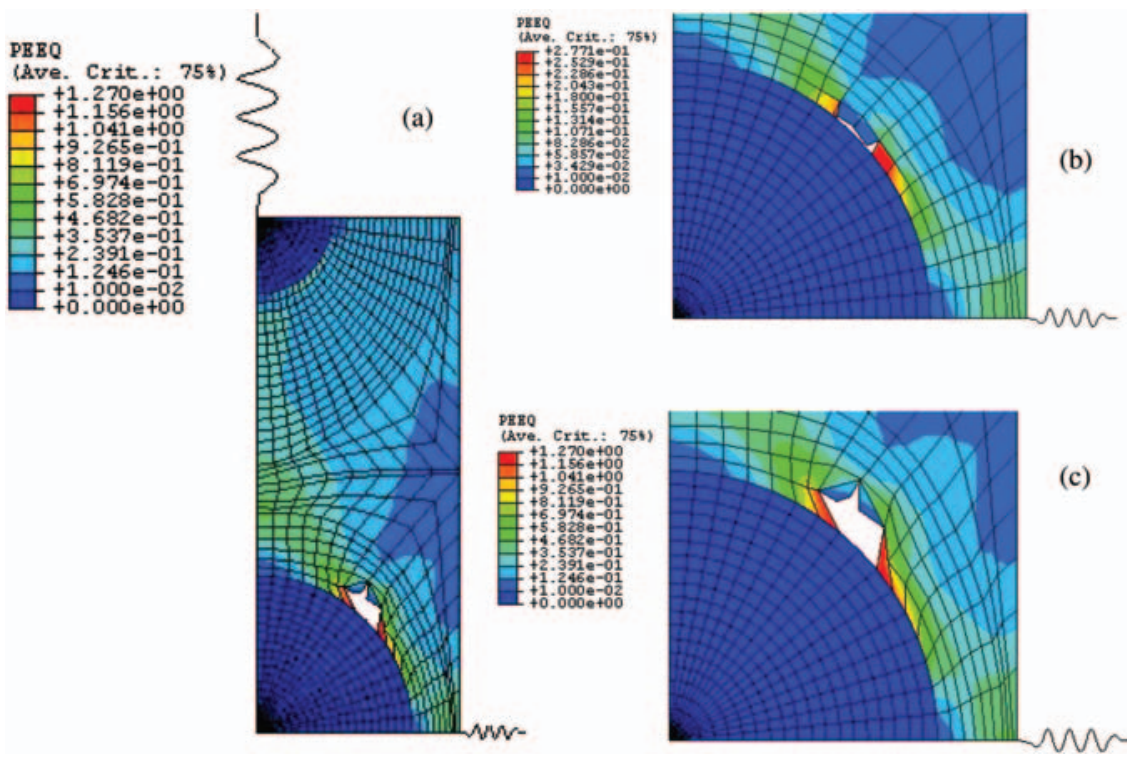

Figure $5 b$. (a) Contours of plastic strain for $V_{m}=14 \%$ for void 2 at $13.5 \%$ effective strain and details of void growth at; (b) $4 \%$; and (c) $13.5 \%$ effective strain.

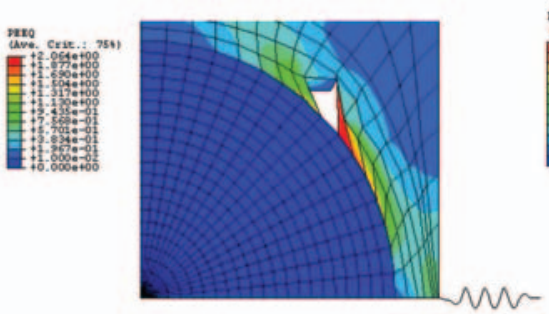

(a)
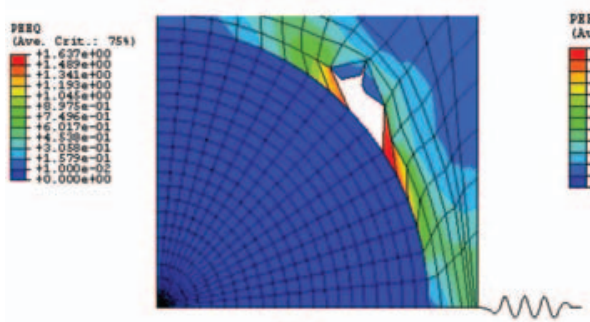

(b)

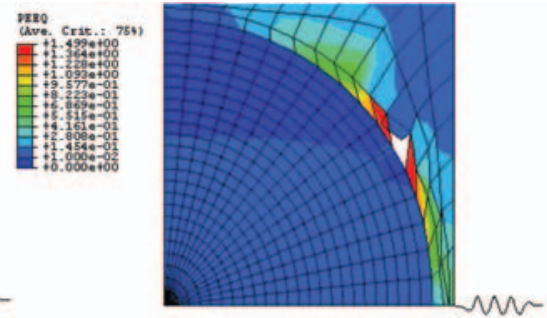

(c)
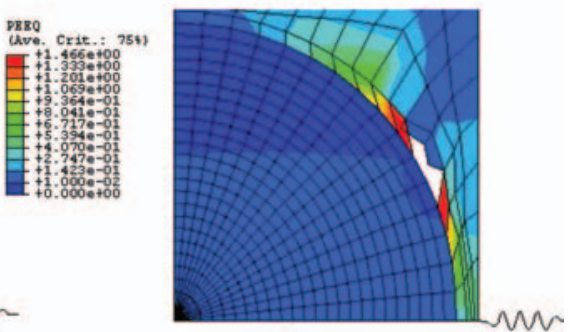

(d)

Figure 5c. Contours of plastic strain for $V_{m}=19.7 \%$ for (a) void 1 at $14.2 \%$ and (b) void 2 at $15.6 \%$ effective strains, and $V_{m}=34 \%$ for (c) void 1 at $9 \%$; (d) void 2 at $10 \%$ effective strains. 
Table 2. Variables determined from stress-strain response of voided micro model.

\begin{tabular}{lccccc}
\hline $\boldsymbol{V}_{\mathrm{m}}(\%)$ & Void & $\boldsymbol{f}_{\mathrm{v}}(\%)$ & $\boldsymbol{\sigma}_{\mathrm{y}}(\mathrm{MPa})$ & $\boldsymbol{\sigma}_{\mathrm{h}}(\mathrm{MPa})$ & $\boldsymbol{\sigma}_{\mathrm{e}}(\mathrm{MPa})$ \\
\hline \multirow{2}{*}{14} & Void 1 & 0.35500 & 648.950 & 766.670 & 629.340 \\
\multirow{3}{*}{19.7} & Void 2 & 1.08413 & 648.950 & 721.800 & 594.500 \\
& Void 1 & 0.49500 & 741.000 & 853.990 & 714.170 \\
34 & Void 2 & 1.73665 & 734.000 & 788.422 & 651.150 \\
& Void 1 & 0.52157 & 649.390 & 983.163 & 629.421 \\
& Void 2 & 0.83343 & 667.460 & 953.380 & 610.350 \\
\hline
\end{tabular}

Table 3. Parameters determined by solving the GT yield function.

\begin{tabular}{cccc}
\hline & $\boldsymbol{V}_{\mathbf{m}}=\mathbf{1 4 \%}$ & $\boldsymbol{V}_{\mathbf{m}}=\mathbf{1 9 . 7 \%}$ & $\boldsymbol{V}_{\mathbf{m}}=\mathbf{3 4 \%}$ \\
\hline$q_{1}$ & 1.900 & 2.331 & 2.574 \\
$q_{2}$ & 1.210 & 1.012 & 0.905 \\
\hline
\end{tabular}

The calibrating parameters for each $V_{\mathrm{m}}$ are summarized in Table 3 . These calibrating parameters are determined by substituting the variables determined in Table 2 into the GT model for the two void cases.

\section{SIMULATION OF A TENSILE BAR TEST}

The response of a tensile bar for the three $V_{\mathrm{m}}$ considered is simulated to assess the ability of the calibrated GT model to capture localization and fracture at the macro scale. The tensile bar is modeled using symmetry conditions, which reduces the problem to one-fourth the model size. The necking is triggered at the center of the model by marginally reducing the radial dimension at that spot. The mesh is finer in the middle where necking occurs and coarsens away from the middle uniformly. The measurements on the model are done at a corresponding gauge length $(25.4 \mathrm{~mm})$ performed experimentally, to be able to compare the model predictions to the experimental results. The model was made with 330 axisymmetric eight node reduced integration elements and 1099 nodes.

The model predictions in terms of the computed normalized load versus elongation are shown in Figure 6 compared to representative experimental results obtained in this work. The plot of the tensile bar showing the necking at failure with contours of plastic strain for the three $V_{\mathrm{m}}$ considered are shown in Figure 7. The GT model with the calibrating parameters determined in this work (Table 3) was used in performing these simulations. 

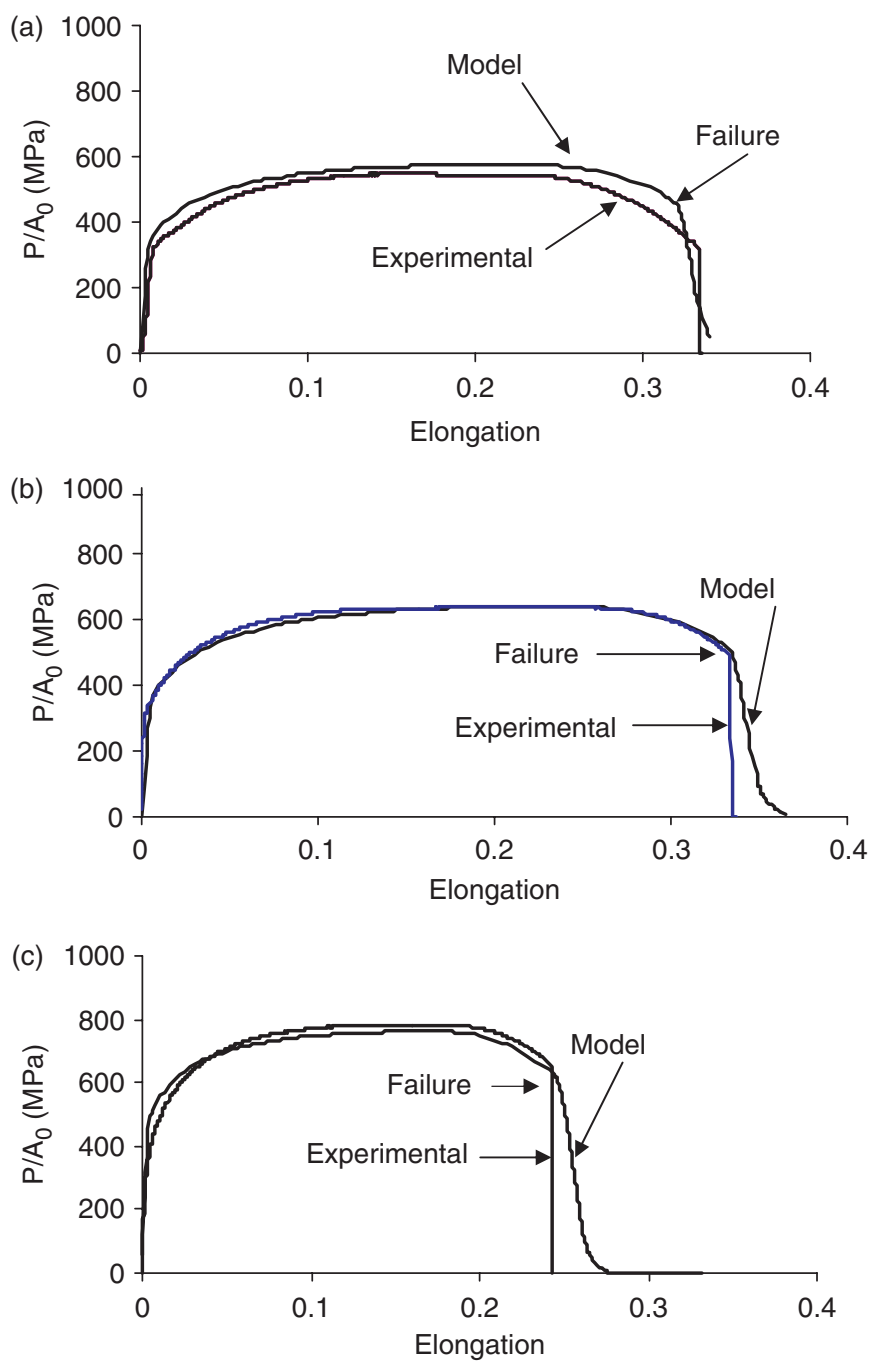

Figure 6. Comparison between tensile bar model prediction and representative experimental results for (a) $V_{m}=14 \%$; (b) $19.7 \%$; and (c) $34 \%$.

The growth of voids and nucleation of new voids was introduced in the GT model by the following Equation (Tvergaard, 1982):

$$
\mathrm{d} f_{\mathrm{v}}=\mathrm{d} f_{\text {nucl. }}+\mathrm{d} f_{\text {gr. }}
$$




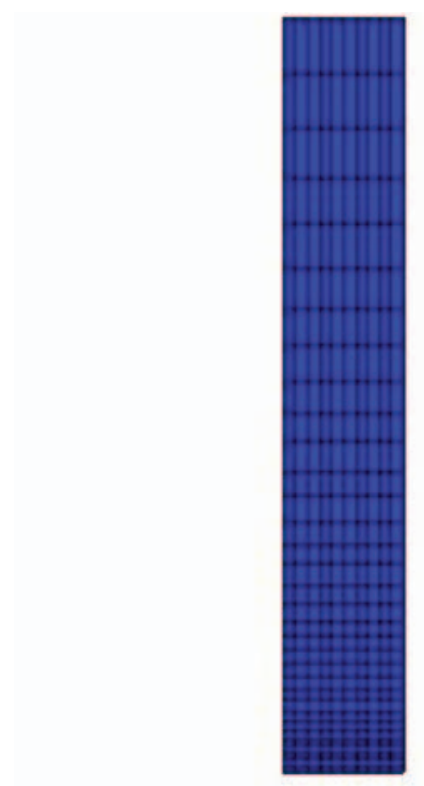

\section{PERQ}

(Ave. Crit.: 75\%)

T +1.109 e+00

+1.032 eto

$+9.555 \mathrm{e}-01$

$+9.555 \mathrm{e}-01$
$++8.786 \mathrm{e}-01$
+
$+8.017 \mathrm{e}-01$
$+7.248 \mathrm{e}-01$

$+6.479 \mathrm{e}-01$

$+5.710 \mathrm{e}-01$

+
$+4.941 \mathrm{e}-01$
$+4.172 \mathrm{e}-01$
$+3.403 \mathrm{e}-01$

$+2.634 \mathrm{e}-01$

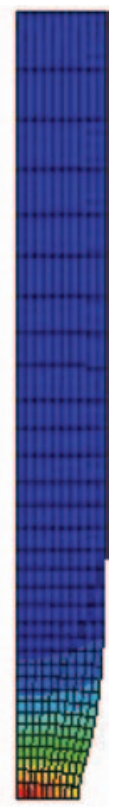

PEBQ

(Ave. Crit.: 75\%)

$+8.235 \mathrm{e}-01$

$+7.717 \mathrm{e}-01$

$+7.200 \mathrm{e}-01$

$+6.683 \mathrm{e}-01$

$+5.648 \mathrm{e}-01$

+5.131 e-01

$+4.614 \mathrm{e}-01$

$+4.614 \mathrm{e}-01$

$+4.096 \mathrm{e}-01$

$+3.062 e-01$

$+2.545 \mathrm{e}-01$

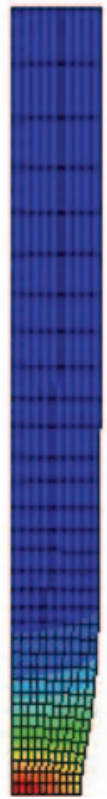

(a)

(b)

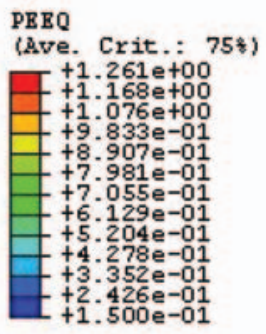

(c)

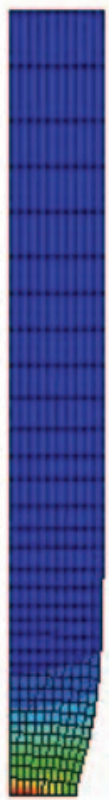

Figure 7. Contours of plastic strain showing necking of the tensile bar model at fracture: (a) mesh design; (b) $V_{m}=14 \%$; (c) $V_{m}=19.7 \%$; and (d) $V_{m}=34 \%$. 
And the total void volume fraction determined as:

$$
f_{t}=f_{0}+f_{\text {nucl. }}+f_{\text {gr. }}
$$

In numerical modeling, the void nucleation is generally written in two parts, namely, the stress-controlled and strain-controlled quantities. Gurson (1977) and Goods and Brown (1979) have shown that the nucleation of voids could be correlated to the equivalent plastic strain. Although there are a number of workers that have reported the correlation to equivalent stress, the strain-controlled model will be used in this work. Void nucleation and void growth are respectively defined in ABAQUS (Hibbitt et al., 2002):

$$
\begin{aligned}
\mathrm{d} f_{\text {nucl. }} & =A \mathrm{~d} \varepsilon_{\mathrm{e}}^{p}+B\left(\mathrm{~d} \sigma_{\mathrm{h}}+\mathrm{d} \sigma_{\mathrm{e}}\right) \\
\mathrm{d} f_{\mathrm{gr}} & =\left(1-f_{\mathrm{v}}\right) \operatorname{trace}\left(\mathrm{d} \varepsilon_{i j}^{p}\right)
\end{aligned}
$$

where $A$ and $B$ are strain and stress controlled void nucleation intensity parameters, respectively, $\sigma_{\mathrm{e}}$ is the effective (von Mises) stress, $\sigma_{\mathrm{h}}$ is the hydrostatic stress, $\varepsilon_{e}^{p}$ is the effective plastic strain, and $\varepsilon_{i j}^{p}$ are components of the plastic strain tensor. The nucleation parameters for the strain-controlled case is defined in ABAQUS (Hibbitt et al., (2002):

$$
A=\frac{f_{\mathrm{N}}}{S_{\mathrm{N}} \sqrt{2 \pi}} \exp \left[\frac{-1}{2}\left(\frac{\varepsilon_{\mathrm{e}}^{p}-\varepsilon_{\mathrm{N}}}{S_{\mathrm{N}}}\right)^{2}\right]
$$

where $f_{\mathrm{N}}$ is the volume fraction of particles or inclusions (or volume fraction of existing voids), $\varepsilon_{\mathrm{N}}$ is the mean nucleation strain, and $S_{\mathrm{N}}$ is the corresponding standard deviation. In this work, these values are taken as, $\varepsilon_{\mathrm{N}}=0.3, S_{\mathrm{N}}=0.1$ (Chu and Needleman (1980)) and $f_{0}$ was taken as 0.0002 (Ishikawa et al., 2000). The value of $f_{\mathrm{N}}$ was taken as 0.012 (Ishikawa et al., 2000), 0.023, and 0.023 for $V_{\mathrm{m}}=14,19.7$, and $34 \%$ respectively. At low $V_{\mathrm{m}}$ the $f_{\mathrm{N}}$ parameters are taken the same as what Ishikawa et al. (2000) have reported, but at intermediate and high $V_{\mathrm{m}}$ the values are chosen to be 0.023 , since at low $V_{\mathrm{m}}$ the deformation mechanics and mechanisms are very similar to plain carbon steels, but at intermediate and high $V_{\mathrm{m}}$ the mechanics and mechanisms of deformation are quite different as shown in Al-Abbasi and Nemes (2003a,b) and Al-Abbasi and Nemes (2007). Although the parameters work well for the model describing the fracture behavior of DP-steels, rationally it would 
be better to investigate the nucleation parameters for DP-steels, which is beyond the scope of this work.

The constitutive behavior of the material considered for the corresponding $V_{\mathrm{m}}$ is obtained from the predictions of the micromechanical model reported in Al-Abbasi and Nemes (2007), which can be used in the numerical simulation of any geometry. The composite is assumed as an elastic-plastic solid and the flow stress, $\sigma$, and the plastic strain, $\varepsilon_{\mathrm{p}}$, to be related as follows:

$$
\sigma=K\left(\varepsilon_{0}+\varepsilon_{p}\right)^{n}
$$

The parameters $K, \varepsilon_{0}$, and $n$ are determined from a fit of the true stress versus true strain response from the micro model from the strain of $0.2 \%$ to the uniform elongation. The resulting parameters as shown in Table 4 for the three levels of $V_{\mathrm{m}}$, are utilized in the tensile bar simulations. As can be seen from Figure 6 , the predictions produced by the simulations of the tensile bar agrees very well with the experimental results produced in this work. The model can predict the yield strength, hardening behavior, and the UTS for all the levels of $V_{\mathrm{m}}$ considered in this work. More importantly, the model can capture the onset of failure where the material suddenly losses its load carrying capacity (Figure 6(a)).

The parameters in the GT equation can also be determined from results given by Faleskog et al. (1998). For the ranges of $V_{\mathrm{m}}$ investigated in this work, the corresponding parameters can be determined by using Table 4 and results from Faleskog et al. (1998) and linearly interpolating and/or extrapolating to get the constants corresponding to the hardening of each $V_{\mathrm{m}}$, and the yield stress to the stiffness ratio. The yield strength to stiffness ratio for $V_{\mathrm{m}}=14,19.7$, and $34 \%$ are $0.001882,0.003571$, and 0.002371 , respectively.

Figure 8 depicts the results of the simulation of a tensile bar using the parameters from Faleskog et al. (1998) compared to the results obtained in this work. The simulation predictions obtained by employing the calibration parameters obtained in this work and the ones determined from Faleskog et al. (1998) results are compared to the experimental findings summarized

Table 4. Parameters used to describe the macroscopic material behavior.

\begin{tabular}{lccc}
\hline $\boldsymbol{V}_{\mathbf{m}}(\%)$ & $\boldsymbol{K}$ & $\boldsymbol{n}$ & $\boldsymbol{\varepsilon}_{\mathbf{0}}$ \\
\hline 14.0 & 994 & 0.2118 & 0.0102 \\
19.68 & 1131 & 0.2245 & 0.0129 \\
34.0 & 1220 & 0.1688 & 0.0037 \\
\hline
\end{tabular}



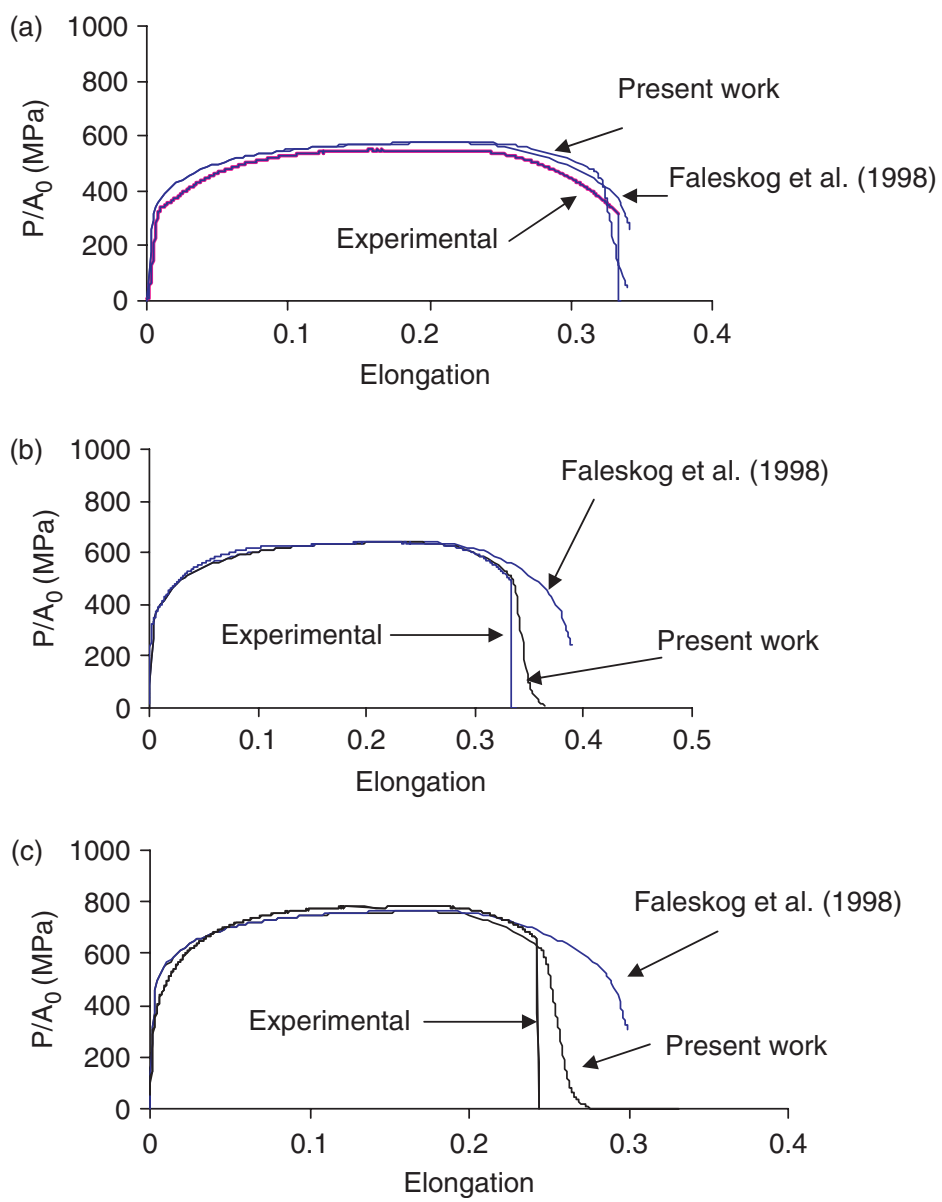

Figure 8. Predicted tensile bar responses from parameters determined in this work and the ones taken from Faleskog et al. (1998) for $V_{m}$ (a) 14\%; (b) 19.7\%; and (c) $34 \%$.

in Table 5. The reduction of area (ROA) and the elongation at fracture are measured at the instant where there is a sudden loss of the load carrying capacity (Figure 6(a)). As can be seen in Figure 8, the predictions of Faleskog et al. (1998) do not show the sharp drop as in the case of the results of the present work, which is closer to the experimental findings. The experimental results show a sudden collapse in the load carrying capacity of the material tested at the three $V_{\mathrm{m}}$ considered, while the predictions using the calibrating parameters from Faleskog et al. (1998) show that the material can still be loaded and as loaded it looses its capacity gradually. The model predictions based on the calibrating parameters 
Table 5. Comparison of the predicted results and the experimental findings, $R O A$ and elongation to fracture.

\begin{tabular}{cccccccc}
\hline & \multicolumn{3}{c}{ Elongation to fracture (\%) } & & \multicolumn{3}{c}{ Reduction of area (ROA) (\%) } \\
\cline { 2 - 3 } \cline { 6 - 8 } & $\begin{array}{c}\text { Current } \\
\text { work }\end{array}$ & $\begin{array}{c}\text { Faleskog } \\
\text { et al. (1998) }\end{array}$ & Experimental & & $\begin{array}{c}\text { Current } \\
\text { work }\end{array}$ & $\begin{array}{c}\text { Faleskog } \\
\text { et al. (1998) }\end{array}$ & Experimental \\
\hline$V_{m}=14.0 \%$ & 32.33 & 34.20 & $32.60-36.81$ & 66.17 & 70.70 & $67.06-71.65$ \\
$V_{m}=19.7 \%$ & 33.73 & 38.86 & $33.46-36.08$ & & 54.02 & 78.30 & $53.94-55.89$ \\
$V_{m}=34.0 \%$ & 24.70 & 29.29 & $22.00-24.41$ & 42.80 & 68.87 & $42.94-49.43$ \\
\hline
\end{tabular}

determined in this work show good agreement with the experimental results both in terms of the ROA and the elongation at fracture. As shown in Table 5 , the elongation to fracture percentage and the ROA percentage predicted in the current work fall within the experimentally observed results. On the other hand, the predictions made using Faleskog et al. (1998) are good as seen from Table 5 for $V_{\mathrm{m}}=14 \%$ but fall outside the experimental range for intermediate and large $V_{\mathrm{m}}$.

\section{CONCLUSIONS}

A procedure was developed in this work to determine the calibrating parameters in the GT model for DP-steels. The procedure determines $q_{1}$ and $q_{2}$ and assumes $q_{3}=q_{1}^{2}$, which is known to be an insensitive parameter. The determination of the parameters is based on employing discrete voids in the micromechanical model developed in previous works, which successfully captures the deformation behavior of DP-steels at different levels of $V_{\mathrm{m}}$. The variables in the GT model, $\sigma_{\mathrm{y}}, \sigma_{\mathrm{e}}, \sigma_{\mathrm{h}}$, and $f_{\mathrm{v}}$ are determined from the response of the micromechanical model with voids (two void size cases) at each $V_{\mathrm{m}}$. These are then used in the GT yield function making up two equations with two unknowns from which $q_{1}$ and $q_{2}$ are obtained. In determining the response of the micro models with voids, the triaxiality in each void size case for a certain $V_{\mathrm{m}}$ is maintained closely at the same values, and at strains corresponding to stress triaxiality $T=1.2$ the variables $\sigma_{\mathrm{y}}, \sigma_{\mathrm{e}}, \sigma_{\mathrm{h}}$, and $f_{\mathrm{v}}$ are determined.

The parameters determined in this work are implemented in a finite element simulation of a tensile test bar to predict elongation at fracture and the ROA. The predicted results agree well with the experimental findings at all levels of $V_{\mathrm{m}}$ considered, as shown in Table 5. The calibrating parameters from Faleskog et al. (1998) show good agreement for low $V_{\mathrm{m}}$ but at intermediate and high $V_{\mathrm{m}}$ the results differ from the experimental range. The deformation behavior of DP-steels shows that the martensite particle 
does not deform plastically at $V_{\mathrm{m}}=14 \%$ and that the deformation is not as complex as in the case of intermediate and high $V_{\mathrm{m}}$. With this being said, the good agreement between the predicted results determined by using calibrating parameters obtained from Faleskog et al. (1998) at low $V_{\mathrm{m}}$ $(14 \%)$ is not surprising as at this level of $V_{\mathrm{m}}$ the localization is not severe, which is similar or close to what happens in plain carbon steel. At intermediate and high $V_{\mathrm{m}}$, however, the deformation behavior is quite complex and very different from plain carbon steel as shown by Al-Abbasi and Nemes (2003a,b) and Al-Abbasi and Nemes (2007), which demonstrates the need for the current model to perform the calibration of the GT parameters. In addition, the simulation results for the tensile bar for parameters obtained from Faleskog et al. (1998) do not show a sudden drop of the load carrying capacity of the model as observed experimentally. With the current parameters, the drop is noticeable which agrees well with experimental findings at the three levels of $V_{\mathrm{m}}$.

\section{REFERENCES}

Abdalla, A.J., Hein, L.R.O., Pereira, M.S. and Hashimoto, T.M. (1999). Mechanical Behavior of Strain Aged Dual Phase Steels, Materials Science and Technology, 15: 1167-1170.

Ahmed, E., Tanvir, M., Kanwar, L.A. and Akhter, J.I. (2000). Effect of Microvoid Formation on the Tensile Properties of Dual-Phase Steel, Journal of Materials Engineering and Performance, 9(3): 306-310.

Al-Abbasi, F.M. and Nemes, J.A. (2003a). Micromechanical Modeling of Dual Phase Steels, International Journal of Mechanical Sciences, 45: 1449-1465.

Al-Abbasi, F.M. and Nemes, J.A. (2003b). Micromechanical Modeling of the Effect of Particle Size Distribution in Dual Phase Steels, International Journal of Solids and Structures, 40: 3379-3391.

Al-Abbasi, F.M. and Nemes, J.A. (2007). Characterizing DP-steels using Micromechanical Modeling of Cells, Computational Materials Science, 39: 402-415.

Balliger, N.K. (1982). Advances in the Physical Metallurgy and Applications of Steels, Book 284, The Metals Society, London.

Chu, C.C. and Needleman, A. (1980). Void Nucleation Effects in Biaxially Stretched Sheets, Journal of Engineering Material and Technology, 102: 249-256.

Davies, R.G. (1978). The Deformation Behavior of a Vanadium-Strengthened Dual Phase Steel, Metallurgical Transactions, 9(A): 41-52.

Faleskog, J., Geo, X. and Shih, F. (1998). Cell Model for Nonlinear Fracture Analysis-I, International Journal of Fracture, 89: 355-373.

Gdoutos, E.E. (1993). Fracture Mechanics, Gladwell G.M.L. (eds), Kluwers Academic Publishers, The Netherlands.

Geo, X., Faleskog, J. and Shih, C.F. (1998). Cell Model for Nonlinear Fracture Analysis-II, Fracture-Process Calibration and Verification, International Journal of Fracture, 89: 375-398.

Gerbase, J., Embury, J.D. and Hobbs, R.M. (1979). The Mechanical Behavior of Some Dual Phase Steels, In: Kot, R.A. and Morris, J.W. (eds), Structure and Properties of Dual-Phase Steels, pp. 118-143, TMS-AIME, New York. 
Gladman, T. (1997). The Physical Metallurgy of Microalloyed Steels, The Institute of Materials, The University Press, Cambridge, London.

Goods, S.H. and Brown, L.M. (1979). The Nucleation of Cavities by Plastic Deformation, Acta Metallurgica, 27: 1-15.

Gurson, A.L. (1977). Continuum Theory of Ductile Rupture by Void Nucleation and Growth: Part I - Yield Criteria and Flow Rules for Porous Ductile Media, Journal of Engineering Materials and Technology, 99: 2-15.

Hibbitt, H.D., Karlsson, B.I. and Sorenson, E.P. (2002). ABAQUS Standard Theory Manual, ABAQUS Inc., Version 6.3-1.

Ishikawa, N., Parks, D.M., Socrate, S. and Kurihara, M. (2000). Micromechanical Modeling of Ferrite-Pearlite Using Finite Element Unit Cell Models, Iron and Steel Institute of Japan International, 40(11): 1170-1179.

Kang, S. and Kwon, H. (1987). Fracture Behavior of Intercritically Treated Complex Structure in Medium-Carbon 6 Ni Steel, Metallurgical Transactions, 18(A): 1587-1592.

Kim, N.J. and Thomas, G. (1981). Effect of Morphology on the Mechanical Behavior of Dual Phase Fe/2Si/0.1C Steel, Metallurgical Transactions, 12(A): 483-488.

Koo, J.Y. and Thomas, G. (1977). Design of Duplex Low Carbon Steels for Improved Strength In: Davenport, A.T. (ed), Weight Applications. Formable HSLA and Dual Phase Steels, pp. 40-55, AIME, New York.

Korzekwa, D.A., Lawson, R.D., Matlock, D.K. and Krauss, G. (1980). A Consideration of Models Describing the Strength and Ductility of Dual-Phase Steels, Scripta Metallurgica, 14: $1023-1028$.

Nam, W.J. and Bae, C.M. (1999). Microstructure Evolution and its Relation to Mechanical Properties in a Drawn Dual-Phase Steel, Journal of Material Science, 34: 5661-5668.

Rashid, M.S. (1977). GM 980X-A Unique High Strength Sheet Steel with Superior Formability, Paper 760206, Soc. Auto. Eng. Cong., Detroit, pp. 938-949.

Rashid, M.S. and Cprek, E.B. (1978). Relationship Between Microstructure and Formability in Two High-Strength, Low-Alloy Steels, Formability Topics - Metallic Materials, ASTM STP 647, American Society for Testing and Materials, Philadelphia, PA, pp. 174-190.

Speich, G.R. and Miller, R.L. (1979). Mechanical Properties of Ferrite-Martensite Steels, In: Kot, R.A. and Morris, J.W. (eds), Structure and Properties of Dual-Phase Steels, pp. 145-182, TMS-AIME, New York.

Steinbrunner, D.L. and Krauss, G. (1988). Void Formation during Tensile Testing of Dual Phase Steels, Metallurgical Transactions, 9(A): 579-589.

Sun, S. and Pugh, M. (2002). Properties of Thermo Chemically Processed Dual-Phase Steels Containing Fibrous Martensite, Materials Science \& Engineering, 335: 298-308.

Szewczyk, A.F. and Gurland, J. (1982). A Study of The Deformation and Fracture of a Dual-Phase Steel, Metallurgical Transactions, 13(A): 1821-1826.

Tvergaard, V. (1981). Influence of Voids on Shear Band Instabilities Under Plane Strain Conditions, International Journal of Fracture Mechanics, 17: 389-407.

Tvergaard, V. (1982). On Localization in Ductile Materials Containing Spherical Voids, International Journal of Fracture, 18: 237-252.

Tvergaard, V. and Needleman, A. (1984). Analysis of the Cup-Cone Fracture in a Round Tensile Bar, Acta Metallurgica, 32: 157-169. 